IIIIIIIIIIIIIII

Note

IIIIIIIIIIIIII

\section{Fate of aged tolclofos-methyl and diethofencarb residues in soil}

\author{
Rika KodAKA* and Toshiyuki KatAgI \\ Environmental Health Science Laboratory, Sumitomo Chemical Co., Ltd., \\ 4-2-1 Takatsukasa, Takarazuka, Hyogo 665-8555, Japan
}

(Received June 14, 2011; Accepted August 31, 2011)

The fate of bound residues originating from ${ }^{14} \mathrm{C}$-labeled tolclofos-methyl and diethofencarb was examined in the presence and absence of organic amendments. After 3-month incubation with ${ }^{14} \mathrm{C}$-labeled pesticides at $20 \pm 2^{\circ} \mathrm{C}$ under dark conditions, the equivalent weight of fresh soil or organic matter $(0.3 \%$ dry weight basis) was added to the soil and further incubated for six months to investigate the effect of additions on the bound residues. Only $4-11 \%$ of aged ${ }^{14} \mathrm{C}$-residues was extracted with aqueous organic solvents, indicating that most of them tightly bound to soil. Addition of fresh soil or organic matter caused slightly higher mineralization than in control soil, resulting in the $11-24 \%$ release of bound ${ }^{14} \mathrm{C}$ six months after additions. Although bound residues in aged soil were found not to be easily released even by organic solvents, they could be utilized by microbes and gradually mineralized. (c) Pesticide Science Society of Japan

Keywords: Biodegradation of pesticides in soil, bioavailability, bound residues.

\section{Introduction}

Pesticides undergo various transformations, including hydrolysis, photolysis and microbial degradation, in the environment, with a fraction escaping from the field via volatilization and run-off. In a metabolism study of radio-labeled pesticide, a radioactive fraction remained after appropriate solvent extraction without changing the nature of the residue, ${ }^{1)}$ called "bound residue." This is considered to be tightly associated with soil via hydrophobic interactions and/or chemical reactions with humic substances and entrapment in the soil microenvironment. The bound residues generally increase with ageing and become less bio-available. ${ }^{2-4)}$ Recently, the release of pesticide residue from the bound fraction in aged soil became a concern as one of the possible routes of environmental contamination. ${ }^{5,6)}$ The fractions of a pesticide and its metabolites bound to soil may be released over time and become available to plants and soil organisms. Although little is known about the nature of bound residues, ${ }^{13} \mathrm{C}$ - and ${ }^{15} \mathrm{~N}-\mathrm{NMR}$ spectroscopy has been applied to elucidate their chemical nature. ${ }^{7-9)}$ Mineralization experiments of bound residues have also been con-

\footnotetext{
* To whom correspondence should be addressed.

E-mail: kodaka@sc.sumitomo-chem.co.jp

Published online January 6, 2012

(C) Pesticide Science Society of Japan
}

ducted to examine their bioavailability ${ }^{10-12)}$ and some microflora showed mineralization ability towards bound residues remaining even after Soxhlet extraction. ${ }^{13)}$ The objective of the present study was to examine the fate of aged pesticide residues through mineralization experiments by taking account of the usual agronomical practices such as tillage and organic additions. Microbial activity in soil contributing to mineralization was mimicked by the addition of fresh soil, glucose and pulverized straw as model practices.

\section{Materials and Methods}

Tolclofos-methyl (I) [O,O-dimethyl O-(2,6-dichloro-4-methylphenyl)phosphorothioate] and diethofencarb [isopropyl 3,4diethoxycarbanilate] (II) were used as model pesticides. The chemical structures of I and II uniformly labeled with ${ }^{14} \mathrm{C}$ at each phenyl ring ${ }^{14,15)}$ are shown in Table 1, together with their specific activities.

Radioactivity in aqueous and organic extracts of soil and trapping media was individually measured by liquid scintillation counting (LSC) with a Packard Model 2900TR liquid scintillation analyzer using liquid scintillation cocktails Emulsifier Scintillator Plus ${ }^{\circledR}$ (Perkin-Elmer). Unextractable soil residues were powdered after air-drying at room temperature by a mill mixer MM301 (Retsch) and a portion was subjected to combustion analysis using a Packard Model 307 Sample Oxidizer with ${ }^{14} \mathrm{C}$ recovery of $>97 \%$. The determination of ${ }^{14} \mathrm{CO}_{2}$ as well as other analytical details was similar to those previously reported. ${ }^{16,17)}$

The extracts were individually analyzed by reversed phase high-performance liquid chromatography (HPLC). A Hitachi L-2130 liquid chromatograph equipped with a Sumipax ODS A-212 column $(5 \mu \mathrm{m}, 6-\mathrm{mm}$ i.d. $\times 15 \mathrm{~cm}$; Sumika Chemical Analysis Service, Ltd., Osaka) was operated at a flow rate of


$\% \mathrm{~A}$ (acetonitrile)-\%B (0.05\% formic acid), 10:90; 0-30 min, linear, $90: 10$ at $30 \mathrm{~min} ; 30-40 \mathrm{~min}$, isocratic, $90: 10$ at $40 \mathrm{~min}$; $40-42 \mathrm{~min}$, linear, $10: 90$ at $42 \mathrm{~min} ; 42-60 \mathrm{~min}$, linear, isocratic, $10: 90$ at $60 \mathrm{~min}$. UV absorbance at $254 \mathrm{~nm}$ was monitored with a Hitachi model L-6200 UV detector. The radioactivity of column effluent was monitored with a Flow Scintillation Analyzer 610TR (PerkinElmer) equipped with a 500-mL liquid cell using UltimaFlo AP (PerkinElmer) as a scintillator. Each ${ }^{14} \mathrm{C}$ peak was identified in HPLC co-chromatography by comparing its retention time with those of non-radiolabeled authentic standards detected by the UV detector. The typical retention times of I and II were 32 and $25 \mathrm{~min}$, respectively.

Commercial standard soil $5 \mathrm{M}$ (sandy loam, sand/silt/clay= 61.7/27.7/10.6; $\mathrm{pH}\left(\mathrm{CaCl}_{2}\right)$ 7.2, $\mathrm{pH}$ (water) 7.8; organic carbon content, $1.2 \%$; 2 -mm sieved) provided by LUFA Speyer (Germany) was moistened with distilled water at $50 \%$ of maximum waterholding capacity and pre-incubated at $20 \pm 1^{\circ} \mathrm{C}$ in darkness for 2 weeks. Each $\left[{ }^{14} \mathrm{C}\right]$ label in $300-\mu \mathrm{L}$ acetonitrile was dropwise added to $40 \mathrm{~g}$ of each soil sample (dry-weight basis) at an application 
Table 1. Chemical structures and properties of ${ }^{14} \mathrm{C}$-I and II

\begin{tabular}{lll}
\hline Compound & Chemical structure & $\begin{array}{c}\text { Specific activity } \\
\text { Radiochemical purity }\end{array}$ \\
[phenyl-14 $\mathrm{C}]$ \\
Tolclofos-methyl
\end{tabular}

*: ${ }^{14}$ C-labeled position

rate of $1 \mathrm{ppm}$, mixed well and incubated for about three months at $20 \pm 1^{\circ} \mathrm{C}$ in darkness. Humidified air was continuously passed over soil samples into two gas-washed bottles each containing $300 \mathrm{ml}$ ethylene glycol and $0.5 \mathrm{M}$ aqueous $\mathrm{NaOH}$ solution in sequence to trap volatile ${ }^{14} \mathrm{C}$. The soil moisture content was adjusted to its original level by the addition of distilled water once a month.

To compare the effect of soil microbial biomass on the aged residues of ${ }^{14} \mathrm{C}$-I or $\mathbf{I I}$, after 3 -month incubation, ${ }^{14} \mathrm{C}$-treated soil ( $20 \mathrm{~g}$ on a dry-weight basis) was added to the same weight of 2 -week pre-incubated fresh soil, followed by thorough mixing. In the case of aged soil with ${ }^{14} \mathrm{C}$-I, $0.3 \%$ glucose (Wako Pure Chemical Industries, Ltd.) or finely ground rice straw (dry weight basis) was added 0 and 5 months post-addition to examine the effect of the additional carbon source easily utilized by microbes. Control soils were incubated continuously without any addition.

The "aged ${ }^{14} \mathrm{C}$-residues" before each addition were determined in duplicate by extracting three times with $100 \mathrm{~mL}$ of $0.01 \mathrm{M}$ aqueous $\mathrm{CaCl}_{2}$ solution by mechanical shaking for 16 $\mathrm{hr}$, followed by centrifugation at $5000 \mathrm{rpm}$ for $10 \mathrm{~min}$. A $1-\mathrm{mL}$ aliquot of each extract was radioassayed in duplicate by LSC. The aqueous layer containing $>2 \%$ of the applied ${ }^{14} \mathrm{C}$ was acidified with $1 \mathrm{M} \mathrm{HCl}$ and extracted twice with $80 \mathrm{~mL}$ ethyl acetate. The soil residues were further extracted three times with $80 \mathrm{~mL}$ methanol and then methanol/0.1 M HCl (9/1, v/v) in the same manner as described above except for a shaking time of $10 \mathrm{~min}$. The extracts were individually radioassayed and concentrated to dryness in vacuo for HPLC analyses. The unextractable soil-bound residues were dried and powdered, and a portion (ca. $200 \mathrm{mg}$ ) was combusted using a sample oxidizer prior to LSC.

During six-month incubation after additions at $20 \pm 1^{\circ} \mathrm{C}$ in darkness, soil samples were periodically taken in duplicate and similarly analyzed as above with volatile ${ }^{14} \mathrm{C}$ at appropriate intervals. Microbial population under each soil condition was conveniently measured by the plate count method, using $1.5 \%$ agar medium containing Nutrient Broth (Difco) for bacterial and actinomycetous colonies and Potato Dextrose Broth (Difco) with streptomycin (Wako Ltd., $30 \mu \mathrm{L} / \mathrm{mL}$ ) for fungal populations.

\section{Results and Discussion}

In order to simulate the release of pesticide from soil under natural conditions, $0.01 \mathrm{M}$ aqueous $\mathrm{CaCl}_{2}$ solution was used as the first extraction medium. Immediately after application, the recovery of ${ }^{14} \mathrm{C}$-I and II was 15.9 and $65.3 \%$, respectively, which was accounted for by the difference in the $K_{\mathrm{oc}}$ value (I, 1650-6140; II, 270). ${ }^{18)}$ Most of the remaining radioactivity was recovered by the second extraction with methanol (I, 75.8\%; II, 27.8\%) and trace amounts of radioactivity could only be obtained by harsh extraction with methanol/HCl solution (I, 1.8\%; II, 1.0\%). The resultant unextracted bound residues after three extractions were $2.5 \%$ for I and $11.2 \%$ for II. After 3-month incubation, $55.7 \%$ or $79.9 \%$ of applied ${ }^{14} \mathrm{C}$ remained in soil treated with ${ }^{14} \mathrm{C}$-I or II as aged ${ }^{14} \mathrm{C}$ residues, respectively.

The data after additions are expressed as percentages of this remaining ${ }^{14} \mathrm{C}$ in soils, i.e., sum of the radioactivity in the three extracts and unextractable soil-bound residues just before the addition were regarded as " $100 \%$ " by setting the date of amendment as day 0 . For aged ${ }^{14} \mathrm{C}$ residues arising from ${ }^{14} \mathrm{C}$-I, the radioactivity in each extraction after one month amounted to $2-6 \%$ in all cases, gradually decreased over time and $c a$. $70 \%$ of the unextracted bound residues remained after six months (Figs. 1-3). Glucose treatment seemed to slightly increase the total extractable radioactivity concomitant with decreasing the unextracted bound residues. More I was found to be released from glucose-treated soil by a factor of 2.1-2.7, as compared with the control and other additions after one month, but this enhanced factor subsequently decreased to 1.2-1.9. There was no significant effect either on the extractability of ${ }^{14} \mathrm{C}$ or the amount of released $\mathbf{I}$ by the addition of fresh soil or ground straw. The change of soil $\mathrm{pH}$ may affect the release of ${ }^{14} \mathrm{C}$ from soil, but this was unlikely by the insignificant change in $\mathrm{pH}(<0.2)$ by any treatment.

In contrast, the cumulative amount of mineralization clearly increased by three additions in the order of glucose, fresh soil and straw (Fig. 1). Similar changes by the addition of fresh soil were observed for aged residues of ${ }^{14} \mathrm{C}$-II. The steady evolution of ${ }^{14} \mathrm{CO}_{2}$ with decreasing amounts of the extractable fraction suggests the rapid microbial mineralization of released ${ }^{14} \mathrm{C}$ from the bound residues. The second addition after 5 months did not stimulate any mineralization. Tighter binding of the residues to soil matrix was considered to limit the further release of ${ }^{14} \mathrm{C}$ from the bound residues.

Different patterns were observed in the HPLC chromatogram of each extract of both ${ }^{14} \mathrm{C}-\mathrm{I}$ and II. Broad and complex peaks possibly consisting of polar degradates were detected at earlier re-

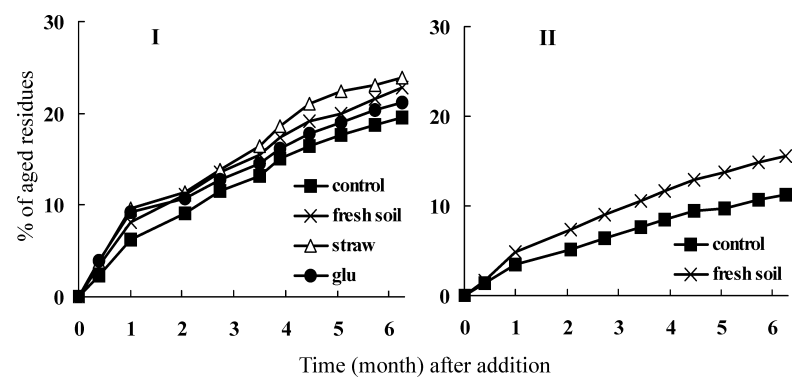

Fig. 1. Accumulative ${ }^{14} \mathrm{CO}_{2}$ under each condition after soil additions. 

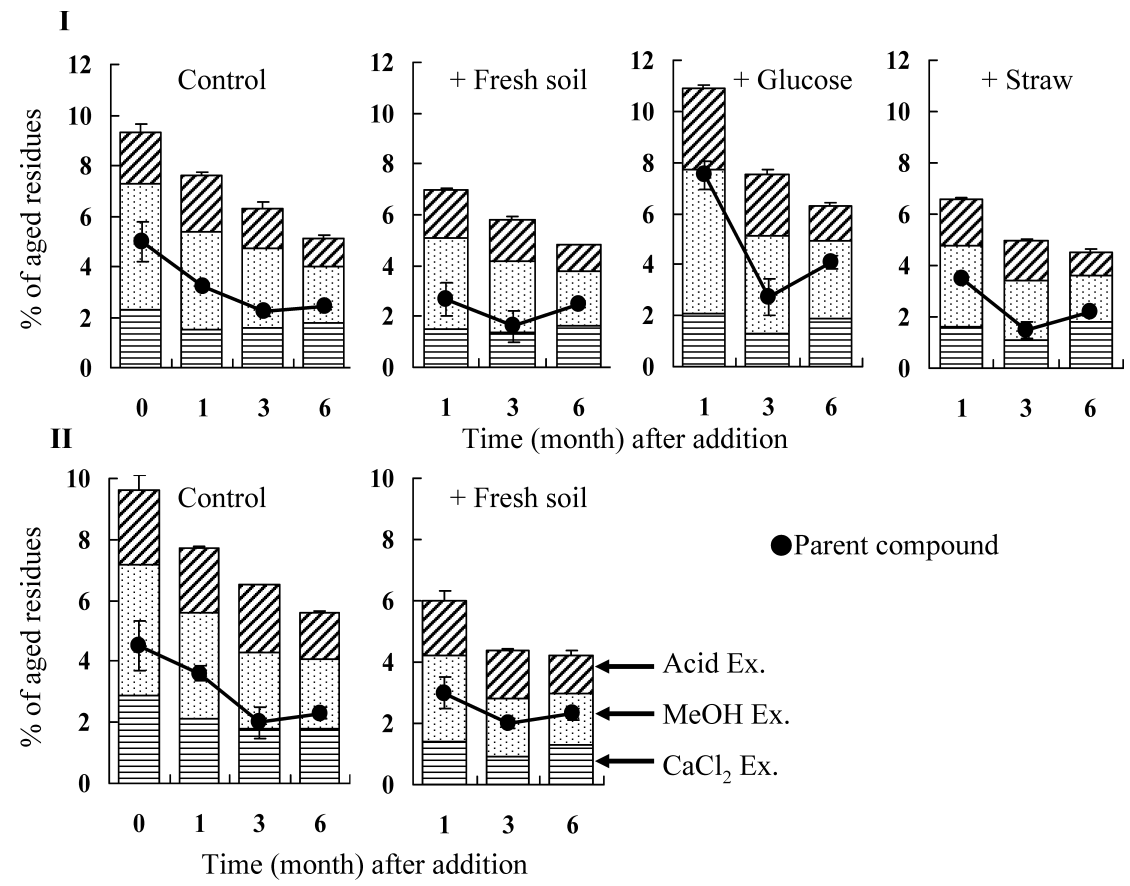

Parent compound

Fig. 2. Distribution of radioactivity among the extracts and the remaining parent compound amount after soil additions.

tention times than the parent pesticide for the extract with $0.01 \mathrm{M}$ aqueous $\mathrm{CaCl}_{2}$ solution. The dominant fraction of methanol and acid extracts was the intact pesticide. These results showed tighter association of the pesticide with soil than their polar metabolites and the pesticide was not easily released by aqueous extraction. Alkaline fractionation ${ }^{19)}$ of the remaining ${ }^{14} \mathrm{C}$ after three extractions showed almost even distribution of ${ }^{14} \mathrm{C}$ into humic and fulvic acids and humin after six months.

Although the microbes forming colonies on agar media are limited, the plate counting method was conveniently used to examine the microbial population in aged soil with ${ }^{14} \mathrm{C}$-I. The number of bacterial and actinomycetous colonies was found to depend on the addition, as shown in Table 2, but insignificant differences were observed for fungi $\left(6.0 \times 10^{4}-2.0 \times 10^{5}, p>0.2\right)$. Addition of fresh soil did not enhance the microbial population, while the addition of glucose or straw increased the number of microbes forming colonies on the agar plate by a factor of 2-20.

Previous reports showed the contradictory effects of soil amendment. ${ }^{20-22)}$ Organic addition sometimes enhanced the dis-

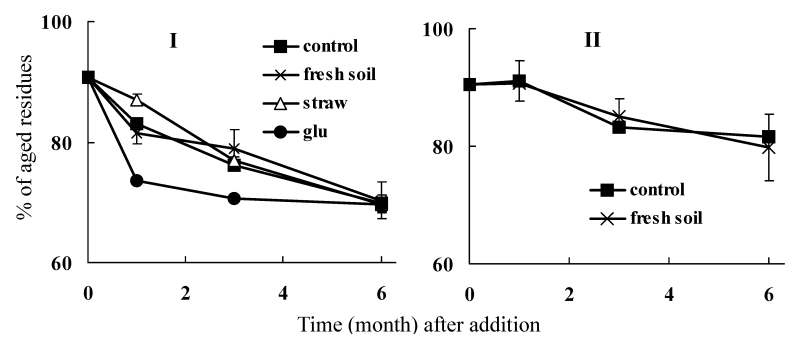

Fig. 3. Amount of unextracted bound residues under each condition after soil additions. sipation of organic chemicals with greater formation of bound residues. In contrast, increased sorption to added organic materials and/or competition for space and nutrients between chemicaldegrading microbes and other microbes increased by addition reduced mineralization. The balance between the high adsorption of $\mathbf{I}$ to soil and the microbial activity after addition resulted in slightly enhanced mineralization. In this study, the gradual evolution of ${ }^{14} \mathrm{CO}_{2}$ for 6 months after addition well coincided with the decrease of the bound residues, as shown in Figs. 1 and 3, indicating that the bound residues were microbially mineralized. Mikami et al. reported that $18-22 \%$ of the unextracted bound residues was mineralized over a 22 -week period using soil with added ${ }^{14} \mathrm{C}$ fenitrothion. ${ }^{13)}$ Although the substituents in the phenyl ring are different between I and fenitrothion, a similar degree of mineralization irrespective of solvent extraction suggests that extraction by aqueous organic solvent even in the presence of acid does not significantly alter the bioavailability of bound residues. Based on these results, the unextracted bound residues not easily released

Table 2. Microbial population (bacteria and actinomycetes) in soil 6 months after addition

\begin{tabular}{lccccccccc}
\hline \multicolumn{8}{c}{ CFU/g dry soil $\left(\times 10^{6}\right)$} \\
\hline & \multicolumn{1}{c}{ control } & \multicolumn{2}{c}{+ soil } & \multicolumn{2}{c}{+ glucose } & \multicolumn{2}{c}{+ straw } \\
\cline { 2 - 9 } & $1 \mathrm{~d}$ & $4 \mathrm{~d}$ & $1 \mathrm{~d}$ & $4 \mathrm{~d}$ & $1 \mathrm{~d}$ & $4 \mathrm{~d}$ & $1 \mathrm{~d}$ & $4 \mathrm{~d}$ \\
\hline Mean & 1.4 & 17 & 1.7 & 12 & 1.7 & 340 & 5.6 & 27 \\
SD & 0.2 & 5.0 & 0.2 & 4.0 & 0.5 & 94 & 0.9 & 6.0 \\
$P$-value & & 0.067 & 0.18 & 0.33 & $5.6 \mathrm{E}-05^{*}$ & $7.1 \mathrm{E}-06^{*}$ & $0.0032^{*}$ \\
\hline \multicolumn{2}{l}{$n=5,{ }^{*}: P<0.05$} & & & & & &
\end{tabular}


by the usual extraction with aqueous organic solvent were clarified to be mineralized upon their release by microbes.

\section{References}

1) OECD Guideline for the testing of chemicals 307 (April 2002).

2) M. Alexander: Environ. Sci. Technol. 29, 2713-2717 (1995).

3) M. Alexander: Environ. Sci. Technol. 34, 4259-4265 (2000).

4) B. Gevao, K. T. Semple and K. C. Jones: Environ. Pollut. 108, 3-14 (2000).

5) G. L. Northcott and K. C. Jones: Environ. Pollut. 108, 19-43 (2000).

6) D. Barraclough, T. Kearney and A. Croxford: Environ. Pollut. 133, 85-90 (2005).

7) K. A. Thorn, J. B. Arterburn and M. A. Mikita: Environ. Sci. Technol. 26, 107-116 (1992).

8) J. Dec, K. Haider, A. Benesi, V. Rangaswamy, A. Schäffer, U. Plüken and J. Bollag: Environ. Sci. Technol. 31, 1128-1135 (1997).

9) H. Knicker, D. Bruns-Nagel, O. Drzyzga, E. V. Löw and K. Steinbach: Environ. Sci. Technol. 33, 343-349 (1999).

10) P. Hatzinger and M. Alexander: Environ. Sci. Technol. 29, 537-545 (1995).

11) J. W. Kelsey, B. D. Kottler and M. Alexander: Environ. Sci. Technol. 31, 214-217 (1997).

12) J. Park, Y. Feng, P. Ji, T. C. Voice and S. A. Boyd: Appl. Environ. Microbiol. 69, 3288-3298 (2003).

13) N. Mikami, S. Sakata, H. Yamada and J. Miyamoto: J. Pestic. Sci. 10, 491-500 (1985).

14) A. Yoshitake, H. Kanamaru, F. Shono and I. Nakatsuka: J. Labelled Compd. Radiopharm. 16, 477-482 (1979).

15) J. Takahashi, S. Nakamura, H. Noguchi, T. Kato and K. Kamoshita: J. Pestic. Sci. 13, 63-69 (1988). 